\title{
Believing as Ourselves
}

\author{
.J. Lynn Jones
}

Beltsville, MD: Amana Publications, 2002. 160 pages.

This book represents the "female" side of a new genre in Islamic publishing. Jones, a white American convert, educated, well-read, and passionate about her native tongue and its literature, writes of her experiences as a female convert to Islam and, as the saying goes, "tells it like it is." Like Jeffrey Lang, who provides the foreword, the author puts into words the confusion, hurt, bewilderment, and anguish that many converts feel after they come down from the giddy heights of "saying their shahadah," - experiences that may all but extinguish the initial spark of excitement and enthusiasm.

The book traces Jones' progress from initial conversion and community involvement, to "burn-out" and withdrawal, and on to her recovery from depression and marital difficulties. In a pattern familiar to many converts, the initial spiritual delight - even euphoria - is soon swamped by layer upon layer of community-induced confusion, rebuffs, snubs, dogmatism, and even racism. She speaks with reference to her interaction with the Arab community, but the pattern will be familiar to many of those who are either converts to Islam and/or partners in mixed marriages.

Jones introduces the Muslim community to the idea of "personal authenticity" and suggests that converts may suffer greatly when they lose their own ethnic or cultural identity in the effort to become more like the born-Muslim community in which they find themselves. While this is an interesting idea, a brief search of such terms via my favorite web search engine led to a host of gay and lesbian sites. Not knowing the precise origin of the notion of "personal authenticity," it would appear to be a matter that should be handled with caution.

The author frankly discusses depression, instead of accepting its being swept under the carpet and dismissed as "madness" or the product of weak faith ... and, therefore, one's own fault. This is another area that deserves the Muslim community's further attention, and in which Jones blazes a longoverdue trail. In addition to the spiritual approach, she provides some practical tools for dealing with it, such as journaling and physical exercise. This brings us back to the issue pertaining to the loss of identity and personal authenticity, as she asks: How can you come to prayer without your heart?

Jones also touches upon women's issues. The chapter on "The American Harlot," which makes for painful reading, highlights the essen- 
tial point that female converts are Muslim women and should be respected as such. Thus, they should not be subjected to suspicion and made objects of gossip and prurient speculation.

A few points in the book are somewhat contentious, such as her comments on hijab and the Arabic language. Her cryptic comments about hijab make one wonder what is in store, although it may be noted that a perennial debate among female converts centers on what kind of hijab we should wear - should we develop our own style or don an imported jilbab and 'abayah and thus look "foreign" in our own land?

With regard to language, the author "raises the flag" of English. There is certainly a need for more fluency and eloquence in Islamic English-language writing. And, as more western-raised Muslims (bornMuslim or converts) enter the writing field, hopes are constantly rising that this ideal will be achieved soon. However, we must be careful to avoid throwing out the proverbial baby with the bath-water and to differentiate between the language and the culture, which may or may not be Islamic per se. Arabic cannot be dismissed out of hand, and Muslims must remain in touch with the Qur'an and the Sunnah, which Allah, in His infinite wisdom, decreed should be revealed in Arabic.

Jones makes several points with regard to Arabic-language $d u$ 'a' and how this may be regarded as futile when one's native language is not Arabic and a person wants to converse with the Almighty from the heart. But it should be noted that no scholar forbids supplication in a language other than Arabic, and that one important purpose of reciting du 'a' in Arabic is emulation of the Prophet. There is no reason why one cannot do both.

The value of this book lies in its providing reassurance to the female convert that she is not alone, and in suggesting some practical means of dealing with potential problems and issues. In addition, this book should be read by community leaders and anyone who wants an insight into the upheavals and trials that many, if not all, convert women face. A step away from preaching, apologetics, and "thou-shalts" (all of which have their time and place), this is the voice of experience, an honest mirror held up to the community - one that shows a warts-and-all picture. Hopefully, this may finally induce the community to tackle these issues. Of equal importance is the fact that it is home-grown Muslim literature, our own voice. 